\title{
SIGNIFICANCE OF FINES IN HOT MIX ASPHALT SYNTHESIS
}

Elvira Kalaitzaki, Civil Engineer, Ph.D. Candidate, Democritus University of Thrace;

George Kollaros, Assistant Professor, Democritus University of Thrace; email: gkoll@ civil.duth.gr

Antonia Athanasopoulou, Associate Professor, Democritus University of Thrace;

Abstract

According to their size, aggregates are classified in coarse grained, fine grained, and fines. The determination of fines content in aggregate materials is very simple and is performed through the aggregate washing during the sieving procedure to define the gradation curve. The very fine material consists of grains having a size lower than $63 \mu \mathrm{m}$. The presence of fines directly influences the composition and performance of concrete and asphalt mixtures (e.g. asphalt content, elasticity, fracture). The strength and load carrying capacity of hot mix asphalt (HMA) results from the aggregate framework created through particle-particle contact and interlock. Fines or mineral filler have a role in HMA. The coarse aggregate framework is filled by the sand-sized material and finally by the mineral filler. At some point, the smallest particles lose contact becoming suspended in the binder not having the particle-particle contact that is created by the larger particles. The overall effect of mineral filler in hot mix asphalt specimens has been investigated through a series of laboratory tests. It is clear that a behaviour influenced by the adherence of fines to asphalt film has been developed. The optimum bitumen content requirement in case of stone filler is almost the same as that for fly ash. It has been found that the percentage of fly ash filler is crucial if it exceeds approximately a value of $4 \%$.

Keywords: fines, hot mix asphalt, aggregate, pavement, additive.

\section{INTRODUCTION}

Depending on their size, aggregates are classified in coarse grained, fine grained, and fines. Filler is the fine grained portion which passes the No. 200 sieve $(0.075 \mathrm{~mm})$, according to ASTM standards, while, according to the European Standard EN 12620, filler is defined as the graded fine aggregate material having maximum grain size $2 \mathrm{~mm}$ and passing the $0.063 \mathrm{~mm}$ sieve at percentages of $70 \%$ to $100 \%$. Commonly, coarse grained and fine grained aggregates will be brought in the asphalt mix production plant in two or more 


\section{ROMANIAN JOURNAL OF TRANSPORT INFRASTRUCTURE}

Kalaitzaki Elvira, Kollaros George, Athanasopoulou Antonia Significance of fines in hot mix asphalt synthesis

separate fractions. Preferably, filler has to be brought and added separately. In such a way, the stability of asphalt mix in filler content is ensured [1].

Originally, mineral fillers were added to dense-graded HMA (Hot Mix Asphalt) paving mixtures to fill the voids in the aggregate skeleton thus reducing the voids in the mixture. A fines-asphalt mortar is formed when fines mix with the asphalt binder. The asphalt binder stiffens or extends upon the addition of fines. In turn, HMA properties could be affected by the afore-mentioned modification of the asphalt binder.

The role of mineral fillers in the performance of asphalt mixes is essential. This role is twofold. First, fillers act as part of the mineral aggregate by filling the voids between the coarser particles in the mixtures and thereby strengthen the asphalt mixture. On the other hand, when mixed with asphalt, fillers form mastic. Mastic is a high-consistency binder or matrix that cements lager binder particles together. Most likely, a major portion of the filler remains suspended in the binder while a smaller portion becomes part of the load bearing framework $[2,3]$.

The type and amount of filler used in hot asphalt mixtures would affect the properties of the mixes. Industrial and by-product wastes are used as replacement of mineral fillers in asphalt mixtures to enhance the properties and performance of asphalt concrete pavements [4].

\section{BACKGROUND}

Extensive investigations have been carried out to evaluate the suitability of different mineral fillers to substitute the costly fillers commonly used, such as ordinary Portland cement and limestone powder. Meanwhile, there are many types of local waste materials that can be successfully used as mineral filler in hot asphalt concrete mixtures in place of ordinary Portland cement and limestone powder, such as waste glass, ceramic, bricks.

In Israel, researches on aggregate and filler properties that have significant influence on the behaviour and durability of bituminous paving mixtures have been conducted [5]. Six types of filler had been used in order to evaluate the physicochemical properties of the fillers, to rheologically characterise filler-asphalt mastics, and determine the strength and durability of sand-asphalt or HMA mixtures.

Several types of mineral fillers, including pulverized limestone, fly ash (fa), and Portland cement, are used worldwide [6, 7]. In 2004, Aljassar et al. [8] compared the effects of two types of mineral fillers on the strength of asphalt 


\section{ROMANIAN JOURNAL OF TRANSPORT INFRASTRUCTURE}

Kalaitzaki Elvira, Kollaros George, Athanasopoulou Antonia Significance of fines in hot mix asphalt synthesis

mixes as measured by Marshall Stability and retained strength. They showed that both pulverized limestone and Portland cement had similar effect on Marshall Stability, when used as filler. In 2013, Al-Saffar [9] investigated experimentally the effect of using different types of fillers, and content, on hot asphalt concrete mixtures. The fillers used were ordinary Portland cement, lime stone powder, and waste glass powder at percentages of $4 \%, 6 \%$ and $8 \%$ by weight of total aggregate. Based on the results of Marshall Tests on mix design of hot asphalt concrete mixtures, for the wearing course, he concluded that $8 \%$ waste glass powder used as filler tends to produce asphalt concrete mixtures with higher Marshall Stability, lower flow, and lower voids in total mix compared to Portland cement and limestone powder fillers.

Stone dust, cement and lime are conventionally used as fillers. In 2013, Ravindra et al. [10] attempted to assess the influence of non-conventional and cheap fillers, such as brick dust and silica fume in bitumen paving mixes. Their work with non-conventional fillers resulted in bituminous mixes presenting satisfactory Marshall Properties though requiring a bit higher bitumen content in order to satisfy the design criteria. The fillers used in the investigation are likely to partly solve the solid waste disposal of the environment.

Since lime is an effective asphalt modifier for improving the moisture resistance of asphalt pavements, is often used as mineral filler in asphalt concrete mixtures. Addition of lime can also improve pavement performance and durability. Hydrated lime added to asphalt can increase penetration and on the other hand can lower the viscosity of asphalt cements [11, 12]. Dartnell [13] performed an investigation adding in asphalt concrete limestone dust, calcined shale and asbestos as fillers. He used the standard Marshall Mix design method and found that calcined shale had better performance as filler than limestone. It has been reported that the worst behaviour had been exhibited by asbestos.

The type and origin of mineral fillers play an important role in asphalt concrete properties. This was concluded, when in a study [14] three fillers of volcanic origin, one lime filler and three fillers prepared in the laboratory by mixing lime filler with different ratios of montmorillonite were used.

Cement is often used as a filler material in asphalt concrete mixtures and it has been reported [15] that improves anti stripping properties of asphalt concrete.

Significant improvements in the moisture resistance characteristics of asphalt concrete mixtures have arisen when fly ash was used as a replacement for Portland cement and hydrated lime [16].

Baig and Al-Abdul Wahab [17] have conducted a research to evaluate the effectiveness in improving the performance of asphalt concrete pavements that 


\section{ROMANIAN JOURNAL OF TRANSPORT INFRASTRUCTURE}

Kalaitzaki Elvira, Kollaros George, Athanasopoulou Antonia

Significance of fines in hot mix asphalt synthesis

hedmanite (rock wool natural fibres) would have if it was used as filler. They also attempted to compare hedmanite with lime as filler and conventional asphalt mix containing crushed stone filler. They have reached to a conclusion that both hedmanite and lime, at certain percentages, can improve the resilient modulus. Meanwhile, the loss in Marshall Stability and tensile strength were higher in hedmanite mixtures than in lime mixes. Hence, better quality asphalt concrete mixtures can be prepared by using lime rather than hedmanite as filler.

Non-conventional fillers on asphalt concrete mixture have also been used by Rahman \& Sobhan [18]. Locally available materials, such as non-plastic sand, brick dust, and ash have been used as a filler replacement and their effect on the performance of asphalt-concrete mixtures has been studied.

The characteristics of asphalt-concrete mixtures with these fillers have been compared with conventional ones using the procedure specified by AASHTO. When non-plastic sand was used, it has been observed that the value of Marshall Stability was comparatively higher than that of mixtures with other non-conventional filler materials. Also, brick dust and ash required higher asphalt content, due to their higher absorption capabilities.

\section{THE ROLE OF MINERAL FILLERS IN ASPHALT MIXTURES}

Mineral fillers play a dual role in asphalt mixtures, first; they act as a part of the mineral aggregate by filling the voids between the coarser particles in the mixtures and thereby strengthen the asphalt mixture, second; when mixed with asphalt, fillers form mastic, a high-consistency binder or matrix that cements lager binder particles together; most likely a major portion of the filler remains suspended in the binder while a smaller portion becomes part of the load bearing framework.

The type and amount of filler used in hot asphalt mixtures would be affecting the properties of the mixes. The use of industrial and by-products wastes as replacement of mineral fillers in asphalt mixtures to enhance the properties and performance of asphalt concrete pavements.

An extensive programme of investigations have been carried out to evaluate the suitability of many types of mineral fillers to substitute the costly common fillers used such as ordinary Portland cement and limestone powder, at mean while, there are many types of local waste materials (recycle) that can be used successfully as a mineral filler in hot asphalt concrete mixtures instead of ordinary Portland cement and limestone powder such as waste of glass, ceramic, bricks. 


\section{ROMANIAN JOURNAL OF TRANSPORT INFRASTRUCTURE}

Kalaitzaki Elvira, Kollaros George, Athanasopoulou Antonia

Significance of fines in hot mix asphalt synthesis

\section{LABORATORY TESTING}

In an effort to investigate the effect of filler type and quantity in asphalt concrete mixtures, a series of laboratory tests have been performed. The concrete prepared had characteristics described in Greek specifications for type of asphalt concrete AC20. Either stone passing the No. 200 sieve of fly ash have been used as filler material in the specimens. The aggregates used had been received from a supplier in Xanthi area and were fluvial in nature. The crushed aggregates were a mixture of different rocks, mainly limestone, sandstones, and granites. Three samples were used to compose an appropriate for asphalt concrete aggregate mix to be used in the testing programme.

In Table 1, the grain size distribution of these materials is listed, along with the limit values posed by Greek specifications.

Table 1. Grain size distribution of aggregates and limits according to Greek specifications for asphalt concrete mixtures

\begin{tabular}{|c|c|c|c|c|c|c|}
\hline \multicolumn{2}{|c|}{ Sieve size } & \multicolumn{3}{c|}{ Aggregate } & \multicolumn{2}{c|}{ Specification } \\
\hline $\mathrm{mm}$ & US & Agg. 1 & Agg. 2 & Agg. 3 & Min & Max \\
\hline 50 & $2 "$ & 100.0 & 100.0 & 100.0 & 100 & 100 \\
\hline 37.5 & $11 / 2^{\prime \prime}$ & 100.0 & 100.0 & 100.0 & 100 & 100 \\
\hline 25 & $1 "$ & 33.2 & 100.0 & 100.0 & 100 & 100 \\
\hline 19 & $3 / 4^{\prime \prime}$ & 4.4 & 100.0 & 100.0 & 90 & 100 \\
\hline 12.5 & $1 / 2^{\prime \prime}$ & 0.2 & 79.1 & 100.0 & & \\
\hline 9.5 & $3 / 8 "$ & 0.2 & 41.5 & 100.0 & 56 & 80 \\
\hline 4.75 & $\# 4$ & 0.2 & 1.5 & 99.9 & 35 & 65 \\
\hline 2.36 & $\# 8$ & 0.2 & 0.7 & 68.8 & 23 & 49 \\
\hline 1.18 & $\# 16$ & 0.2 & 0.7 & 47.1 & & \\
\hline 0.6 & $\# 30$ & 0.2 & 0.7 & 35.7 & & \\
\hline 0.3 & $\# 50$ & 0.2 & 0.7 & 23.3 & 5 & 19 \\
\hline 0.15 & $\# 100$ & 0.2 & 0.7 & 12.5 & & \\
\hline 0.075 & $\# 200$ & 0.2 & 0.7 & 6.1 & 2 & 8 \\
\hline
\end{tabular}

Fly ash has been used as a replacement of mineral aggregate filler in asphalt concrete. It was supplied by the power plant located in Ptolemaida, North-Western Greece which uses lignite rich in calcium in the form of $\mathrm{CaCO}_{3}$. The specific gravity of fly ash was 2.5 . It's grain size analysis has shown that $5 \%$ of the material has a diameter $<0.002 \mathrm{~mm}, 74 \%$ lies in the range between 


\section{ROMANIAN JOURNAL OF TRANSPORT INFRASTRUCTURE}

Kalaitzaki Elvira, Kollaros George, Athanasopoulou Antonia Significance of fines in hot mix asphalt synthesis

$0.002 \mathrm{~mm}$ and $0.075 \mathrm{~mm}$, and the remaining $21 \%$ of the fly ash had a diameter greater than $0.075 \mathrm{~mm}$.

Table 2. Chemical properties of fly ash

\begin{tabular}{|c|c|}
\hline Parameter & Percent of composition \\
\hline $\mathrm{SiO}_{2}$ (silicon dioxide), $\%$ & 29.95 \\
\hline $\mathrm{Al}_{2} \mathrm{O}_{3}$ (aluminum oxide), $\%$ & 10.85 \\
\hline $\mathrm{Fe}_{2} \mathrm{O}_{3}$ (iron oxide), $\%$ & 4.57 \\
\hline $\mathrm{SiO}_{2}+\mathrm{Al}_{2} \mathrm{O}_{3}+\mathrm{Fe}_{2} \mathrm{O}_{3}, \%$ & 45.37 \\
\hline $\mathrm{CaO}$ (calcium oxide), $\%$ & 20.00 \\
\hline $\mathrm{MgO}$ (magnesium oxide), \% & 1.90 \\
\hline $\mathrm{K}_{2} \mathrm{O}$ (potassium oxide), $\%$ & 0.95 \\
\hline $\mathrm{Na}_{2} \mathrm{O}$ (sodium oxide), $\%$ & 0.32 \\
\hline $\mathrm{S}$ (sulfur, $1000^{\circ} \mathrm{C}$ ), \% & 2.92 \\
\hline $\mathrm{C}$ (carbon), \% & 3.80 \\
\hline Loss on Ignition, $\%$ & 13.90 \\
\hline
\end{tabular}

The fly ash is an off-specification ash, meaning it does not meet the Class $\mathrm{C}$ or Class F criteria in ASTM C 618. The chemical properties of fly are given in Table 2, while its grain size distribution is shown in Figure 1.

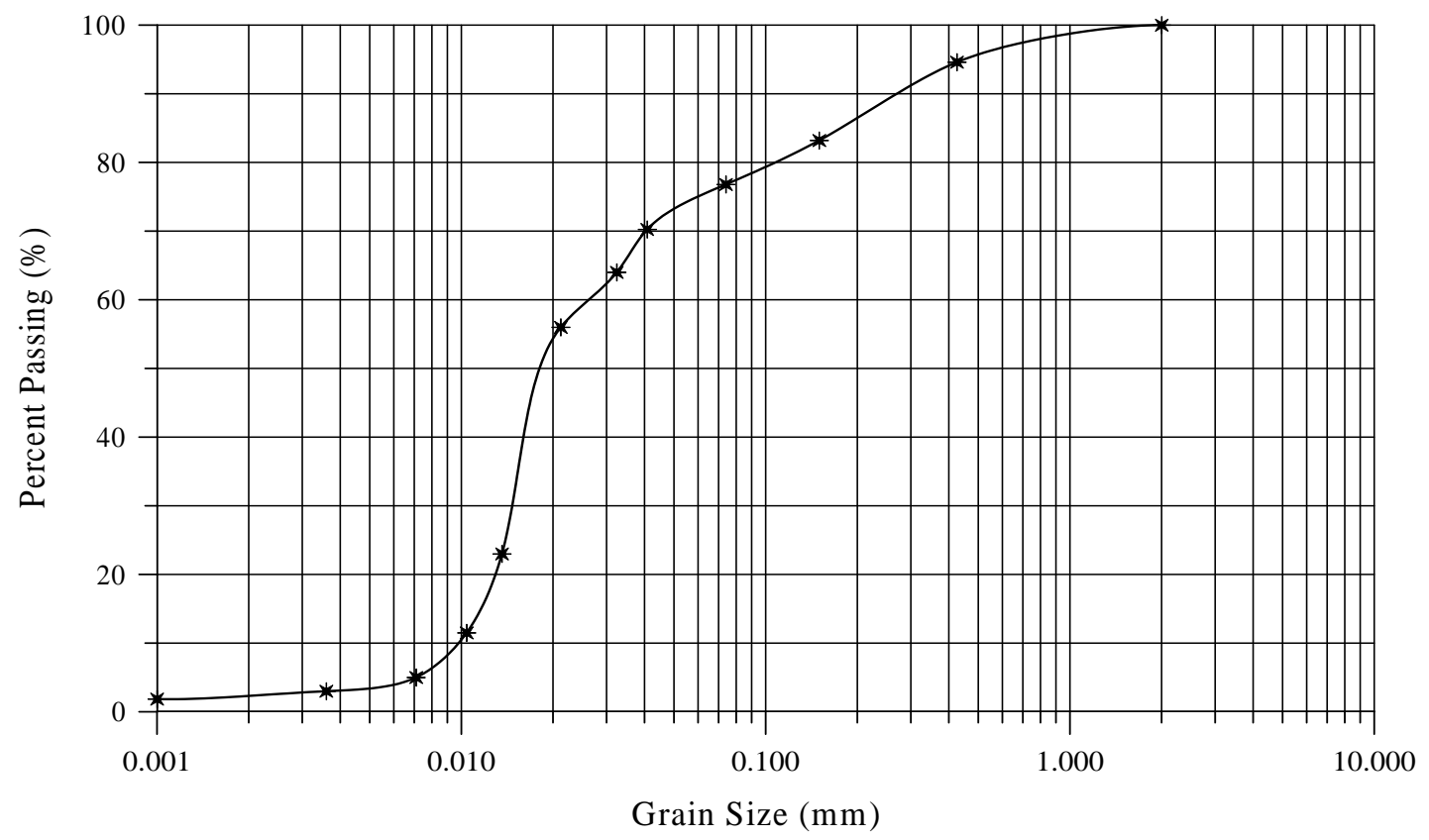

Figure 1. Fly ash grain size distribution 


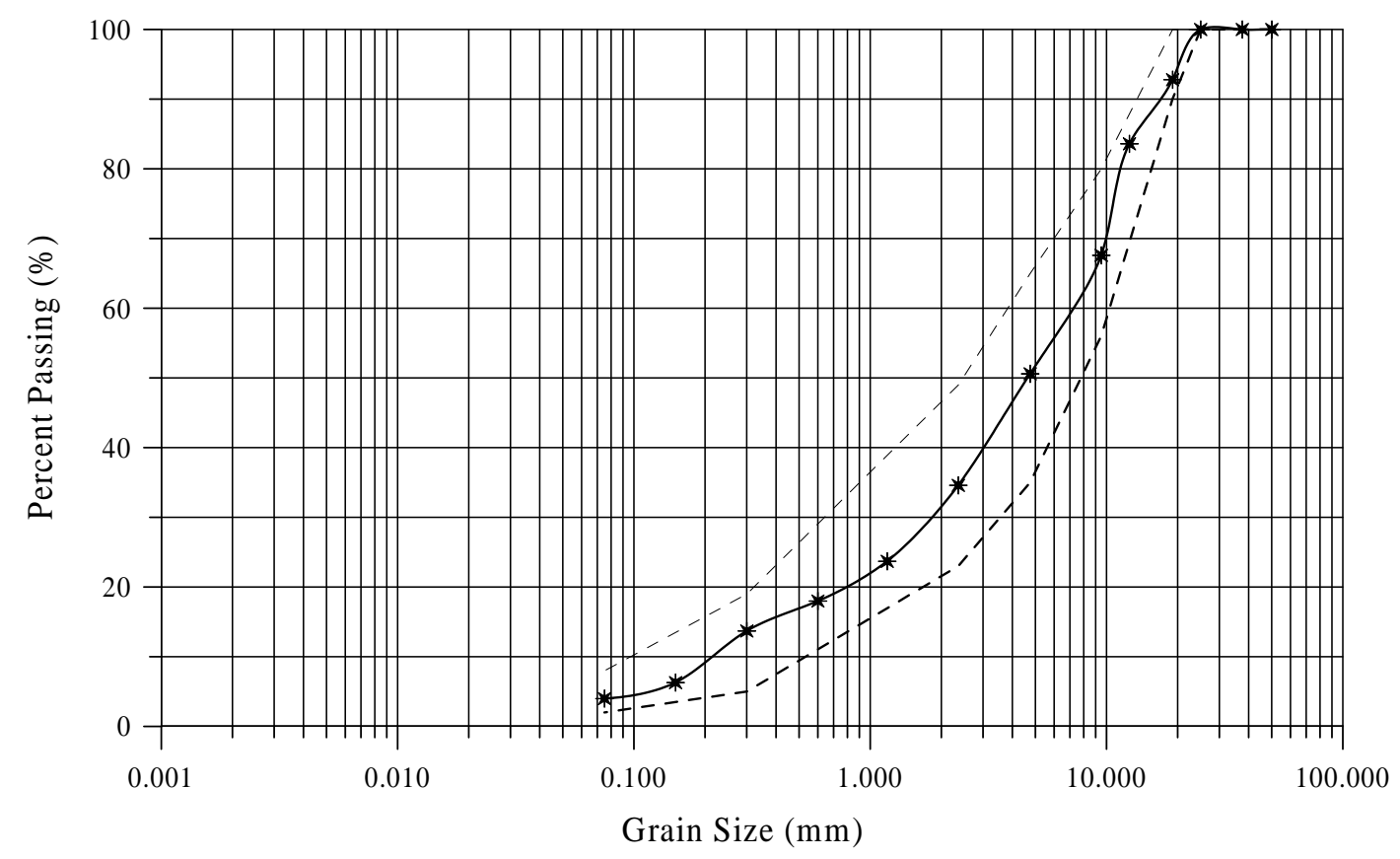

Figure 2. Grain size distribution of composite aggregate mix and specification limits

Cylindrical Marshall specimens were prepared according to ASTM D1559 [19] method using $1200 \mathrm{~g}$ of a composite aggregate having a grain size distribution shown in Figure 2 and paving grade asphalt contents 4, 4.5, 5, and $5.5 \%$. For each percent-age of asphalt, 3 specimens were formed with 75 blows on each face of the specimen. The specimens had been cured for 24 hours in room temperature conditions and left for 30 minutes in water bath of $60^{\circ} \mathrm{C}$ before their placement in the Marshall apparatus for the determination of stability.

The stability, air voids, apparent specific gravity and deformation of the specimens with stone filler and fly ash filler are shown diagrammatically in Figures $3,4,5$, and 6, respectively. 


\section{ROMANIAN JOURNAL OF TRANSPORT INFRASTRUCTURE}

Kalaitzaki Elvira, Kollaros George, Athanasopoulou Antonia Significance of fines in hot mix asphalt synthesis

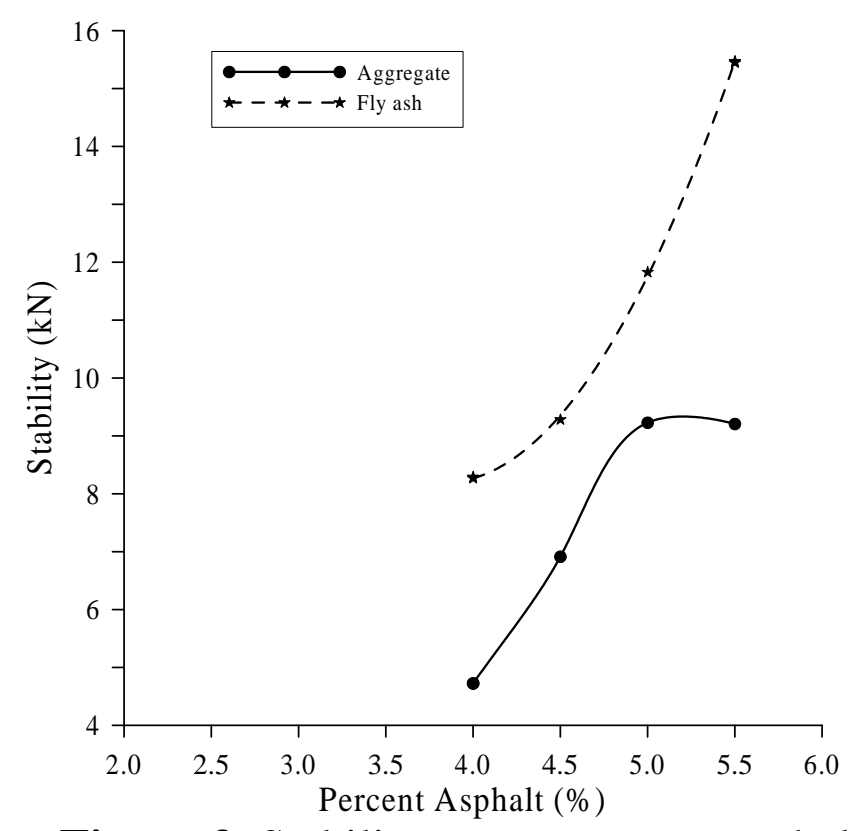

Figure 3. Stability versus percent asphalt for aggregate and fly ash fillers

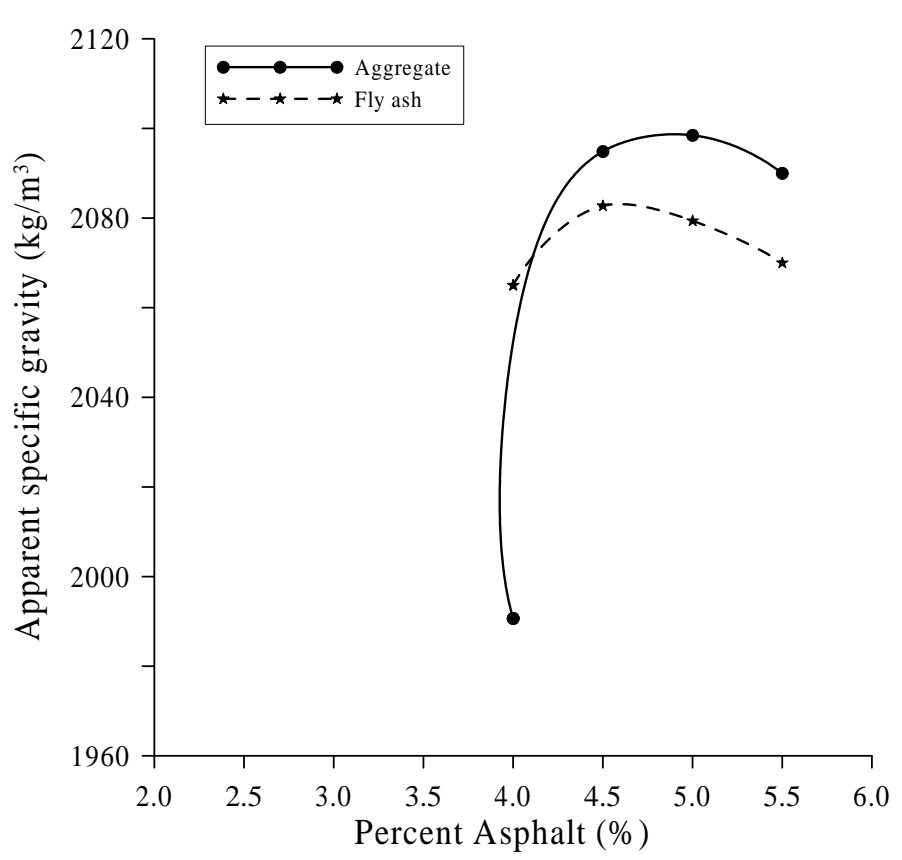

Figure 5. Apparent specific gravity versus percent asphalt for aggregate and fillers

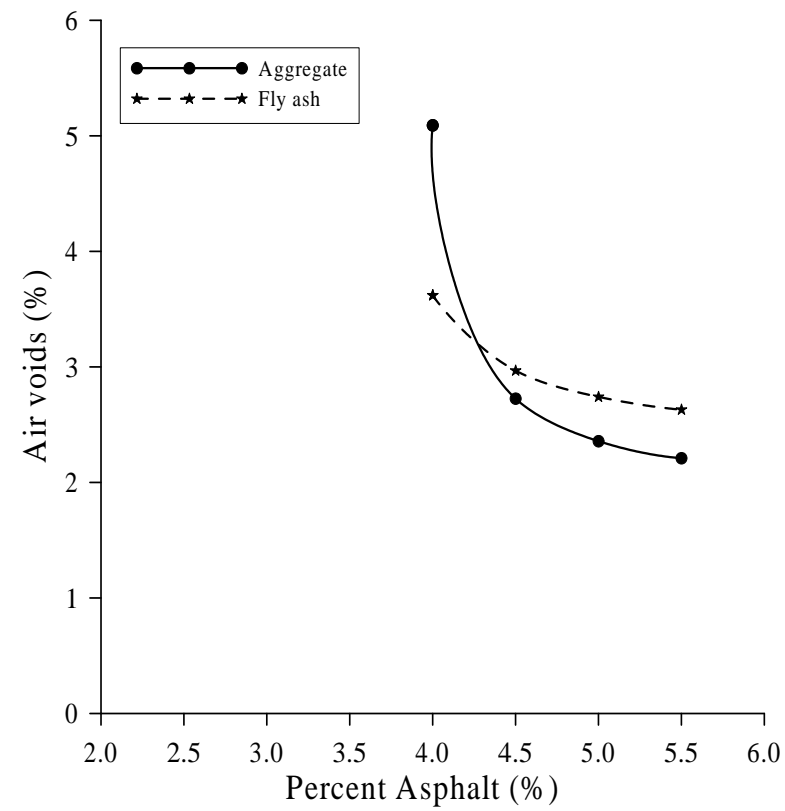

Figure 4. Asphalt mix air voids versus percent asphalt for aggregate and fly ash fillers

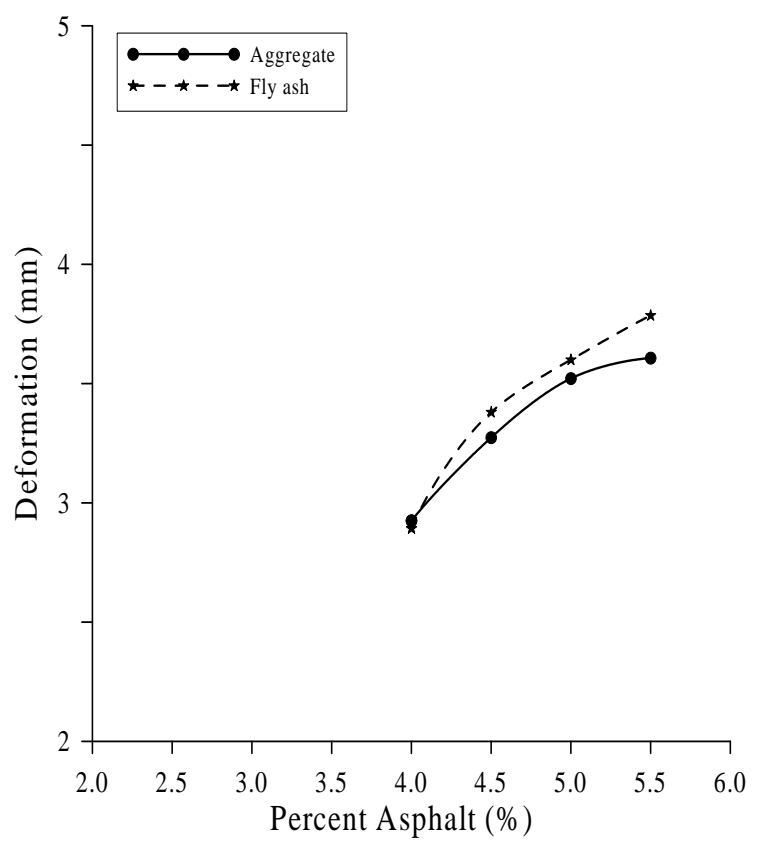




\section{ROMANIAN JOURNAL OF TRANSPORT INFRASTRUCTURE}

Kalaitzaki Elvira, Kollaros George, Athanasopoulou Antonia Significance of fines in hot mix asphalt synthesis

Stability was affected by the addition of fly ash as filler material leading to higher values than in mixtures with stone filler. The range of stability values when fly ash was used as filler covered the interval from 8.29 to $15.45 \mathrm{kN}$. The higher stability value for the specimens with stone filler $(9.23 \mathrm{kN})$ has been obtained for $5 \%$ asphalt content in the specimen.

The air voids contained in samples with fly ash were generally higher than in samples with mineral aggregate filler. Only with $4 \%$ fly ash filler the difference was reverse. The asphalt mixture specimens composed with fly ash as filler material were more workable.

Due to lower weight of fly ash, the apparent specific gravity values of specimens containing fly ash filler ranged in a lower band (2065.00 to 2109.52 $\mathrm{kg} / \mathrm{m}^{3}$ ) compared with those of mixtures having mineral aggregate filler.

The deformation values decreased up to an asphalt percentage of $5 \%$ in both filler cases.

The optimum asphalt content was approximately equal for the two filler materials and about $4.8 \%$. With this percentage of asphalt specimens were prepared having filler contents of 2, 4, 6, and $8 \%$ reducing accordingly the fraction between \#100 and \#200 in the initially defined aggregate composition.

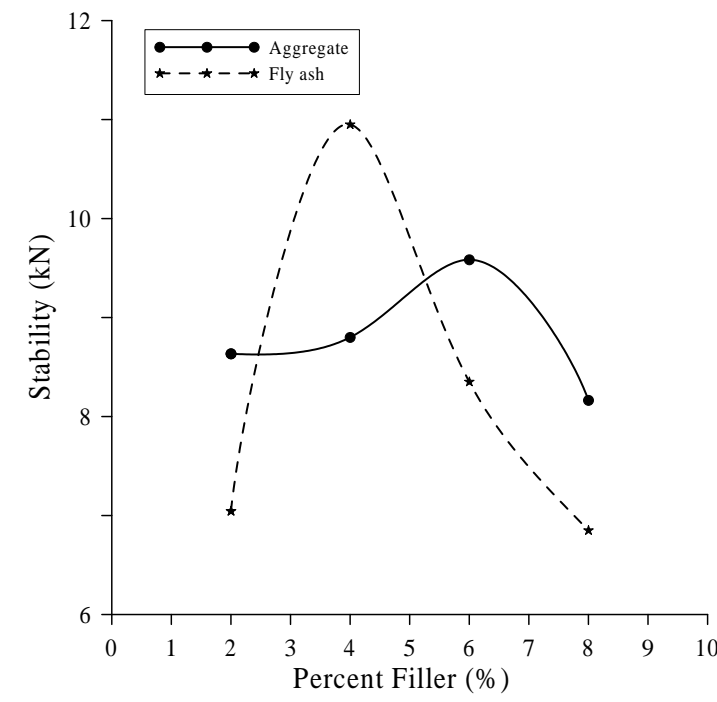

Figure 7. Stability versus percent filler for aggregate and fly ash fillers

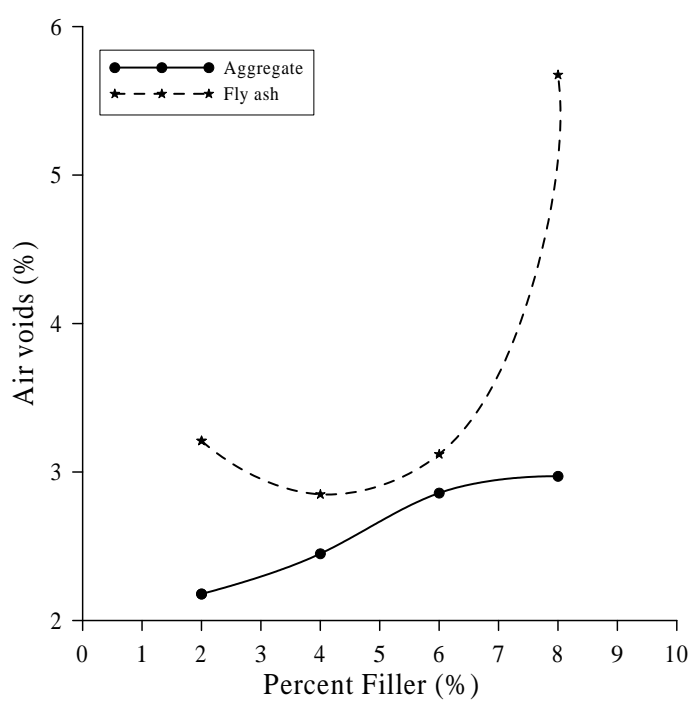

Figure 8. Asphalt mix air voids versus percent filler for aggregate and fa fillers

In Figures 7 to 10 the results of testing in the Marshall apparatus are presented as a function of percent filler, both for stone material and fly ash. The 


\section{ROMANIAN JOURNAL OF TRANSPORT INFRASTRUCTURE}

Kalaitzaki Elvira, Kollaros George, Athanasopoulou Antonia Significance of fines in hot mix asphalt synthesis

behaviour of the asphalt concrete materials was more consistent with the use of mineral aggregate filler. The stability values ranged from 8.16 to $9.58 \mathrm{kN}$.

The $4 \%$ of fly ash added as filler material created a peak on the stability curve $(10.95 \mathrm{kN})$. A corresponding peak has been appeared with $6 \%$ stone filler in the mix. For the same percentage in the mix, fly ash filler occupies larger volume than the stone filler, because the later has a higher specific gravity. This explains why the peaks are in different filler contents.

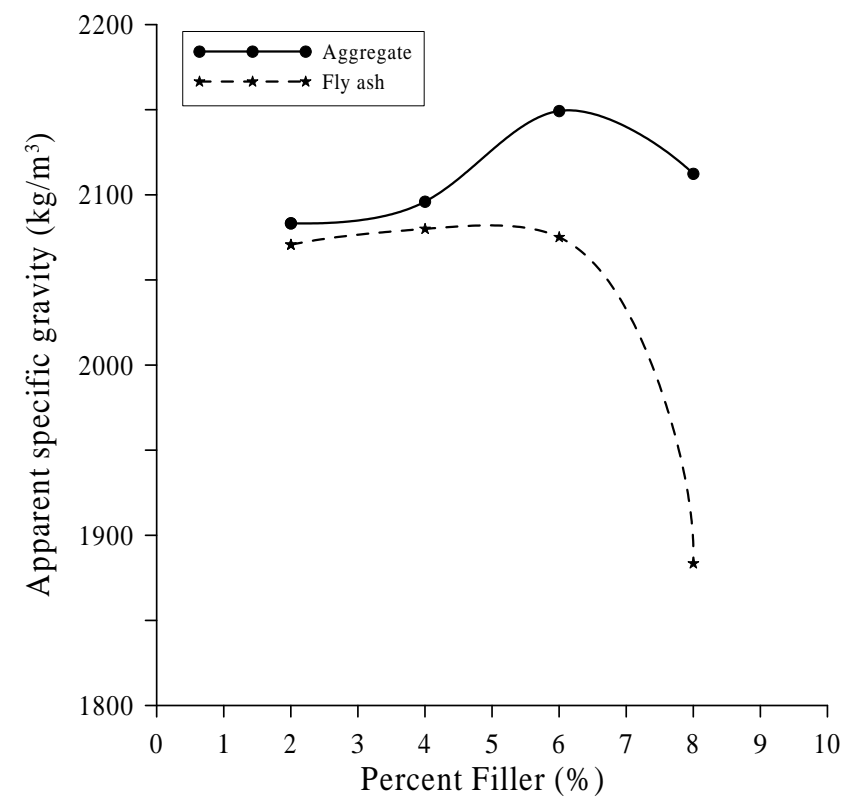

Figure 9. Apparent specific gravity

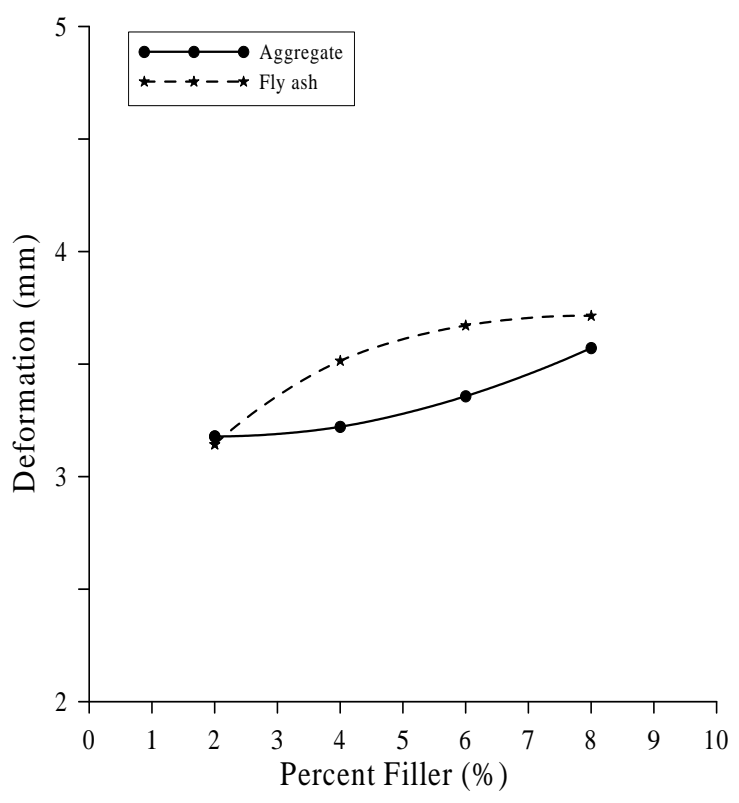

Figure 10. Deformation versus versus percent filler for aggregate and fa percent filler for aggregate and fly ash fillers fillers

Generally speaking, it is preferable to have lack and not excess of filler material. As is seen in Figure 8, the asphalt mix air voids depend on the percent filler for aggregate and fly ash in different ways. Fly ash gave in all percentages added values higher than those resulted when the mineral aggregate was present in asphalt concrete specimens.

The apparent specific gravity versus percent filler for aggregate and fly ash fillers curves had a decreasing slope in both cases. The deformation showed an almost similar trend with the values obtained from aggregate filler being concentrated in a narrower zone than those of the fly ash specimens. 


\section{ROMANIAN JOURNAL OF TRANSPORT INFRASTRUCTURE}

Kalaitzaki Elvira, Kollaros George, Athanasopoulou Antonia

Significance of fines in hot mix asphalt synthesis

\section{CONCLUSIONS}

Based on the experimental programme performed using local materials in Xanthi, Greece, it is verified that inclusion of non-conventional filler can be efficiently used in asphalt-concrete mixture as a filler replacement from the viewpoint of stability, deformation, and voids characteristics.

In this laboratory study, the influence of fly ash, a waste by-product of lignite based thermal power station, as filler on dense graded bituminous concrete paving mixes in terms of various engineering properties, has been investigated. For comparison purposes, fillers normally used in highway construction projects have also been tested.

Hence, it is generally concluded that fly ash can effectively be used as filler in paving mixes in place of most commonly used fillers such as ordinary Portland cement and stone dust. Portland cement returns a high cost and stone dust may be an expensive alternative at certain locations where coarse aggregates are scarce.

Moreover, the use of fly ash in paving mixes may give a solution to the fly ash utilisation and disposal problems and also give a means to make the environment safer and clean. Fly ash is a good option for such a use, since it is cheap, available in huge quantities and needing a way of its removal from free spaces where adversely impacts the environment. Of course, there is a need for further modification in design mixes through technical specifications which can result in utilization of fly ash as filler in bituminous pavement.

The optimum bitumen content requirement in case of stone filler is almost the same as for fly ash. The percentage of fly ash filler is crucial if it exceeds approximately a value of $4 \%$.

\section{REFERENCES}

[1]. ZULKATI, W. DIEW, D. DELAI: D. "Effects of fillers on properties of asphalt concrete mixture”, Journal of Transportation Engineering, vol. 138, No. 7, pp. 902910, 2012.

[2]. B.M. HARRIS, K.D. STEWART: "Analysis of mineral fillers and mastics used in stone matrix asphalt", Journal of the Association of Asphalt Paving Technologists, vol. 6, pp. 54-95, 1995.

[3]. S. WU, J. ZHU, J. ZHONG, D. WANG: "Experimental investigation on related properties of asphalt mastic containing recycled brick powder", Construction Building Materials, vol. 25, No. 6, pp. 2883-2887, 2011. 


\section{ROMANIAN JOURNAL OF TRANSPORT INFRASTRUCTURE}

Kalaitzaki Elvira, Kollaros George, Athanasopoulou Antonia Significance of fines in hot mix asphalt synthesis

[4]. M. RATNASAMY, A. ELTAHER: "The effect of type and particle size of industrial wastes filler on indirect tensile stiffness and fatigue performance of Stone Mastic Asphalt mixtures", Australian Journal of Basic and Applied Sciences, vol. 5, No. 11, pp. 297-308, 2011.

[5]. I. ISHAI, J. CRAUS: "Effects of some aggregate and filler characteristics on behavior and durability of asphalt paving mixtures", Transportation Research Record 1530, Transportation Research Board, National Research Council, Washington, DC, pp. 75-85, 1996.

[6]. P. KUMAR, H.C. MEHNDIRATTA, V. SINGH: "Use of fly ash in bituminous layer of pavement”, Indian Highways, pp. 41-50, 2008.

[7]. V. SHARMA, S. CHANDRA, R. CHOUDHARY: "Characterization of fly ash bituminous concrete mixes", Journal of Materials in Civil Engineering, vol. 22, No. 12, pp. 1209-1216, 2010.

[8]. A.H. ALJASSAR, S. METWALI, M.A. ALI: "Effect of filler types on Marshall Stability and retained strength of asphalt concrete". The International Journal of Pavement Engineering, vol. 5, No. 1, pp. 47-51, 2004.

[9]. $\quad$ H. AL-SAFFAR: "The effect of filler type and content on hot asphalt concrete mixtures properties”, Al-Rafidain Engineering, vol. 21, No. 6, pp. 88-100, 2013.

[10]. T. RAVINDRA, R.K. JAIN, M.H. KOSTHA: "Effect of fillers on bituminous paving mixes", International Journal of Engineering Research \& Science \& Technology, vol. 2, No. 4, pp. 137-142, 2013.

[11]. H.S. DO, P.H. MUN, R. SUK: “A study on engineering characteristics of asphalt concrete using filler with recycled waste lime”, Waste Management, vol. 28, pp. 191-199, 2008.

[12]. J.C. PETERSON: "Lime-treated pavements offer increased durability", Roads and Bridges Journal, vol. 26, No. 1, pp. 85-87, 1988.

[13]. L. DARTNELL: "A study of limestone dust calcined shale and asbestos as mineral fillers in asphalt paving mixtures”, Canadian Tech. Asphalt Assoc. Proceedings, vol. 12, pp. 51-60, 1967.

[14]. B. FUCIC: “Influence of filler types on the properties of bituminous mixtures", Research Report, Zagreb University, Zagreb, 137 p., 1976.

[15]. S.D. RAMSWAMY, M.A. AZIZ: "Assessment of effect of filler on the stripping of bituminous mix". $4^{\text {th }}$ Conference of the Road Engineering Association of Asia and Australasia, Jakarta, Indonesia, vol. 3, pp. 159-170, 1983. 


\section{ROMANIAN JOURNAL OF TRANSPORT INFRASTRUCTURE}

Kalaitzaki Elvira, Kollaros George, Athanasopoulou Antonia Significance of fines in hot mix asphalt synthesis

[16]. J.C. ROSNER, R.D. PAVLOUICH, J.G. CHEHOVITS: "Fly ash as a mineral filler and anti-strip agent for asphalt concrete", Report No. FHWA-AZ-81/173 Washington, DC, FHWA, 1981.

[17]. M.G. BAIG, H.I. AL-ABDUL WAHAB: "Mechanistic evaluation of lime modified asphalt concrete mixtures", ASCE Journal of Materials in Civil Engineering, vol. 10, No. 3, pp. 153-160, 1998.

[18]. M.N. RAHMAN, M.A. SOBHAN: "Use of non-conventional fillers on asphaltconcrete mixture", International Journal of Innovation and Applied Studies, vol. 3, No. 4: pp. 1101-1109, 2013.

[19]. AMERICAN SOCIETY FOR TESTING AND MATERIALS: ASTM D 1559: "Test method for resistance to plastic flow of bituminous mixtures using Marshall Apparatus", Annual Book of ASTM Standards 2000, Sec. 4 - Construction, Vol. 04.03, Road and Paving Materials; Vehicle - Pavement Systems, West Conshohocken, PA. ASTM International, 2000. 